\title{
Bur open Concerning the timing of antibiotic administration in women undergoing caesarean section: a systematic review and meta-analysis
}

\author{
Michael Heesen, ${ }^{1}$ Sven Klöhr, ${ }^{1}$ Rolf Rossaint, ${ }^{2}$ Karel Allegeaert, ${ }^{3}$ Jan Deprest, ${ }^{4}$ \\ Marc Van de Velde, ${ }^{5}$ Sebastian Straube ${ }^{6}$
}

To cite: Heesen M, Klöhr S, Rossaint $\mathrm{R}$, et al. Concerning the timing of antibiotic administration in women undergoing caesarean section: a systematic review and meta-analysis. BMJ Open 2013;3:e002028.

doi:10.1136/bmjopen-2012002028

- Prepublication history and additional material for this paper are available online. To view these files please visit the journal online (http://dx.doi.org/10.1136/ bmjopen-2012-002028).

\section{- Additional material is published online only. To view please visit the journal online (http://dx.doi.org/10. 1136/bmjopen-2012- 002028).}

Received 29 August 2012 Revised 13 February 2013 Accepted 21 March 2013

This final article is available for use under the terms of the Creative Commons Attribution Non-Commercial 2.0 Licence; see http://bmjopen.bmj.com

For numbered affiliations see end of article.

\section{Correspondence to} Dr Michael Heesen; michael.heesen@ sozialstiftung-bamberg.de

\section{ABSTRACT}

Objective: To assess the effects on maternal infectious morbidity and neonatal outcomes of the timing of antibiotic prophylaxis in women undergoing caesarean section. A recent National Institute for Health and Clinical Excellence (NICE) guideline reported that antibiotic administration before skin incision reduces the risk of maternal infection; this recommendation was based on a meta-analysis, however one including trials that were not double blind and not including a trial published recently.

Design: Systematic review and meta-analysis.

Data sources: Searches of PubMed and EMBASE and reference lists of the retrieved articles.

Inclusion criteria: Randomised double-blind controlled trials comparing the administration of antibiotics before skin incision with administration after cord clamping.

Data extraction and analysis: Data on maternal total infectious morbidity, endometritis and wound infection, as well as neonatal intensive care unit admission, neonatal infection and neonatal sepsis were extracted and combined using random effects metaanalysis.

Results: Five studies reporting on 1777 parturients were included in our systematic review. The relative risk (RR) for maternal total infectious morbidity for antibiotic administration before incision compared with antibiotic administration after cord clamping was 0.64 (95\% Cl 0.36 to 1.15). Likewise, there was no difference in the risk of wound infection (RR 0.72 , $95 \% \mathrm{Cl} 0.41$ to 1.27 ). Parturients receiving the antibiotic preoperatively had a significantly reduced risk of endometritis ( $\mathrm{RR} 0.48,95 \% \mathrm{Cl} 0.27$ to 0.87 ; number needed to treat $41,95 \% \mathrm{Cl} 23$ to 165 ). Analyses of the neonatal outcome parameters revealed no differences between the regimens of antibiotic administration, but were based on few studies.

Conclusions: In contrast to a recent NICE guideline, we did not find a reduction in total infectious morbidity with antibiotic administration before skin incision; we confirmed a reduction in the risk of endometritis and a lack of effect on the risk for wound infection.

\section{ARTICLE SUMMARY}

Article focus

- We examined the consequences of the timing of antibiotic administration in caesarean section, before skin incision or after cord clamping.

Key messages

- We found a reduced risk of endometritis but not of total infectious morbidity or wound infection with antibiotic administration before skin incision, in contrast to a meta-analysis in a recent National Institute for Health and Clinical Excellence guideline.

\section{Strengths and limitations of this study}

- We included only double-blind randomised controlled trials.

- There is a relative paucity of data.

The recent update of the National Institute for Health and Clinical Excellence (NICE) guideline $132^{1}$ for caesarean section recommends that administration of prophylactic antibiotics with the aim of decreasing the risk of overall maternal infection should occur before skin incision instead of after delivery. In view of rising concerns about sepsis, at present the leading cause of direct maternal mortality, ${ }^{2}$ this recommendation may appear timely.

However, there is an argument to delay antibiotics until after cord clamping because relevant antibiotic plasma levels are seen in the neonate; ${ }^{3}$ this could potentially affect blood culture results and thereby mask neonatal sepsis.

The NICE guideline states that preincisional antibiotics are more effective in reducing the risk of overall maternal infection than administration after the clamping of the umbilical cord. This recommendation was based on a meta-analysis ${ }^{1}$ - however, one 
including trials that were not double blind ${ }^{45}$ and not including a trial published recently. ${ }^{6}$

The present systematic review aims to identify all relevant randomised controlled double-blind trials comparing antibiotic administration before skin incision with administration after cord clamping in parturients undergoing caesarean section and to perform a meta-analysis of these trials.

\section{METHODS}

A systematic literature search was performed in PubMed and EMBASE with the following search terms: cesarean section or c section or operative delivery or surgical delivery and wound infection or surgical wound infection or postoperative wound infection or abscess or endometritis or urinary infection or urinary tract infection or antibiotic or antibacterial agent. Where possible, the above were used as medical subject headings (MeSH terms). We considered randomised controlled trials (RCTs) published in English, French or German. The date of the last search was 14 June 2012.

We also looked through the bibliographies of the retrieved articles in order to identify further relevant papers.

Two authors (MH and SK) independently reviewed the articles for eligibility. We used the Oxford Quality Scale $(\mathrm{OQS})^{7}$ to assess study quality; quality scoring was performed independently by two authors (MH and SS). A study had to be described as randomised and double blind in order to be eligible for inclusion in our systematic review. Our primary outcome parameter was total infectious morbidity of the mother; secondary outcome parameters were maternal endometritis and maternal wound infection as well as the neonatal outcome parameter's neonatal intensive care unit (NICU) admission, infections, sepsis and suspected sepsis.

A standardised form was used for data extraction, which was performed independently by two authors (MH and SK).

We used the computer programme Review Manager (RevMan, V. 5.1) Copenhagen: The Nordic Cochrane Centre, The Cochrane Collaboration, 2008. The random effects model was used for meta-analyses (to guard against the effects of between-study heterogeneity), pooled relative risks (RR) and 95\% CI were calculated. Numbers needed to treat (NNT) were calculated if the RR was significant.

\section{RESULTS}

Our literature search retrieved 369 hits (figure 1) of which five articles could be included in our systematic review. Details of the included studies, that is, study inclusion and exclusion criteria, name and dose of the applied antibiotics and OQS scores, are presented in table 1 . The five studies ${ }^{6} 8-11$ reported on 1777 parturients in total. All five trials used cefazolin as the antibiotic but there was clinical heterogeneity between the studies, with regard to the dose of the antibiotic and with regard to the inclusion and exclusion criteria used in the studies.

\section{Maternal outcome}

Of the five double-blind RCTs, four studies 68911 did not find a significant difference in total infectious morbidity, one trial ${ }^{10}$ found a significantly lower incidence when the antibiotic was administered before incision. Nokiani et $a l^{11}$ did not clearly state that maternal fever as assessed in their study was due to infection. The meta-analysis of the RCTs without the study by Nokiani $e t a l^{11}$ found an $\mathrm{RR}$ of $0.64,95 \%$ CI 0.36 to 1.15 (figure 2A), indicating no significant difference between preoperative antibiotic administration and administration after cord clamping. For endometritis, a significantly lower risk was found in the parturients receiving the antibiotic before skin incision, RR $0.48,95 \%$ CI 0.27 to 0.87 (figure $2 \mathrm{~B}$ ); the corresponding NNT was 41 (95\% CI 23 to 165). The risk ratio for wound infection was $0.72,95 \%$ CI 0.41 to 1.27 (figure $2 \mathrm{C}$ ). Witt et $a t^{6}$ also reported on urinary tract infections and found $8 / 370$ cases in the group receiving the antibiotic before incision versus 4/371 in the parturients receiving the antibiotic after cord clamping.

\section{Neonatal outcome}

Our analysis of the neonatal outcome parameters is presented in figure 3. Admission to NICU was reported in three trials. ${ }^{9-11}$ We found no significant differences for NICU admission (RR 1.12; 95\% CI 0.60 to 2.07, figure $3 \mathrm{~A}$ ). There were two trials investigating neonatal infection. ${ }^{8}$ Wax et al $l^{8}$ stated that two neonates were treated for pneumonia and two others for febrile illness; all were neonates born to mothers receiving the antibiotic preoperatively. We conducted a meta-analysis of these two trials, assuming that there were four cases with infection in the preoperative group in the study by Wax $e t a l^{8}$; no detail was reported for the group receiving the antibiotic after cord clamping in the study by Wax $e t a l^{8}$ and we assumed that there were no infections in that group. The result of the meta-analysis showed no significant difference (RR $1.65,95 \%$ CI 0.25 to 10.78 , figure $3 \mathrm{~B}$ ).

Cases of neonatal sepsis were reported in three trials $^{9-11}$; our meta-analysis showed no significant difference between the antibiotic administration regimens (RR 1.01; 95\% CI 0.50 to 2.03, figure 3C).

Suspected sepsis was investigated by Wax et al and Thigpen $e t a{ }^{P}$ There was no significant difference between giving the antibiotic before skin incision and after cord clamping (RR 1.14; $95 \%$ CI 0.38 to 3.42 , figure 3D).

\section{DISCUSSION}

We did not find a difference in total infectious morbidity between antibiotic administration before skin incision compared with after cord clamping. 
Figure 1 Selection of articles for inclusion in our systematic review.

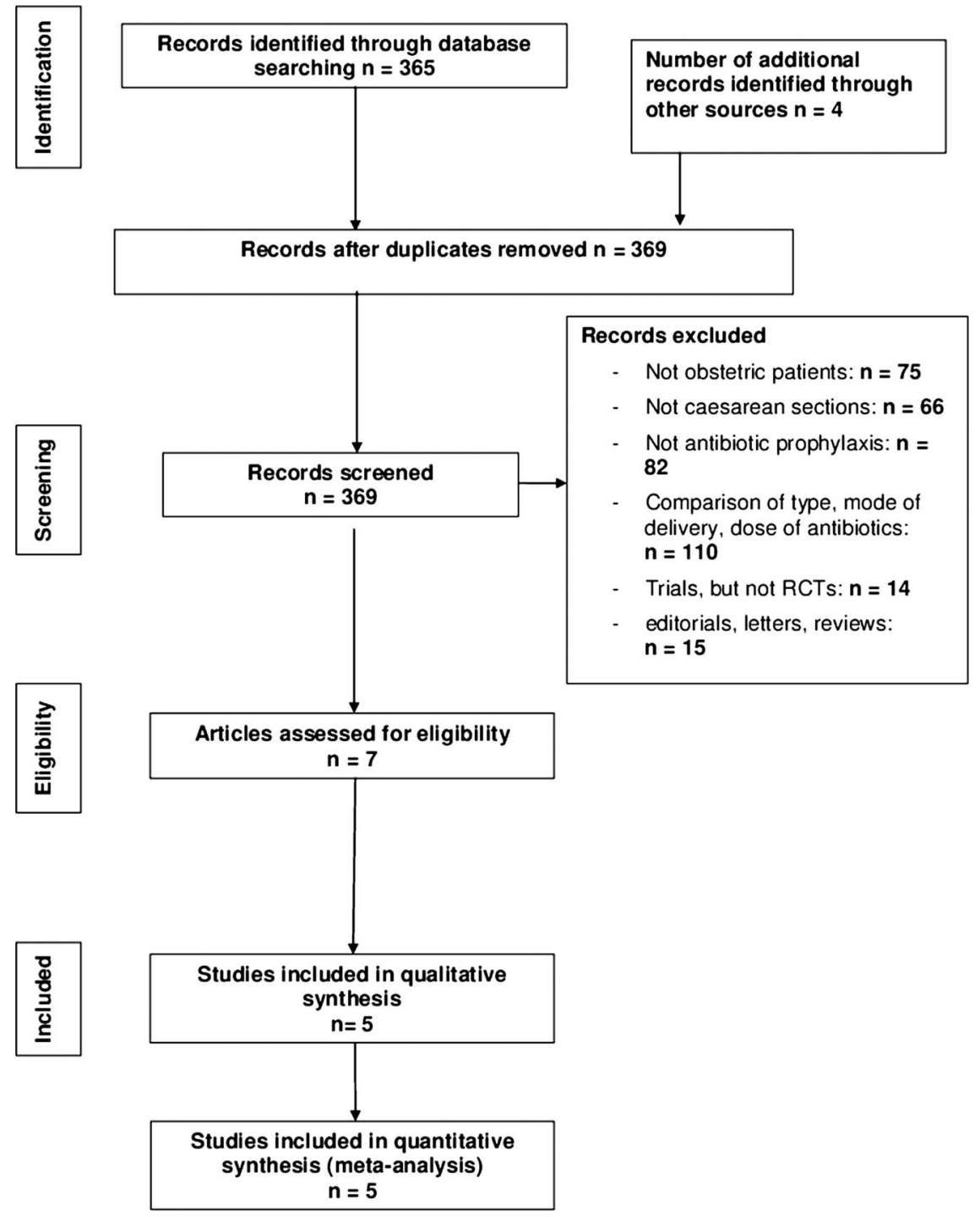

The 2011 NICE guideline on caesarean section recommends to 'offer women prophylactic antibiotics at CS before skin incision. Inform them that this reduces the risk of maternal infection more than prophylactic antibiotics given after skin incision, and that no effect on the baby has been demonstrated.' This recommendation was based on a meta-analysis that included two studies ${ }^{45}$ that were not double blind and that we therefore considered as being of insufficient methodological quality to be included in our systematic review. Furthermore, one trial $^{6}$ was published in 2011 and was not included in the meta-analysis reported by NICE.

Some limitations of our analysis need to be taken into account. First, we based our conclusion on a few trials with a comparatively small number of participants in them. Second, there is clinical heterogeneity between the studies, for example, because of the different doses of cefazolin used.

Our analyses for endometritis and wound infection are in line with the results of the NICE meta-analysis; there was a significant difference in the risk for endometritis and no difference regarding wound infection.

After maternal cefazolin administration for caesarean section, clinically relevant plasma levels have been measured in the infants. ${ }^{3}$ This has prompted concerns for delayed diagnosis of neonatal infection. The NICE guideline concludes that 'no effect on the baby has been demonstrated'. Based on our analysis, we find no convincing evidence favouring either regimen of antibiotic administration in this regard, but again there was a relative paucity of data.

There are several studies with a large number of patients comparing preincisional antibiotic administration with administration after delivery. These studies found significant reductions in endometritis ${ }^{12} 13$ and wound infection. ${ }^{12}{ }^{14}{ }^{14}$ However, these studies were retrospective and not randomised. Thus, they were more susceptible to bias. Furthermore, retrospective chart analyses are often flawed by the incomplete documentation of confounding factors. 
Table 1 Characteristics of studies included in our preferred meta-analysis

\begin{tabular}{|c|c|c|c|c|c|c|c|}
\hline \multirow[b]{2}{*}{ Source } & \multirow[b]{2}{*}{ Inclusion criteria } & \multirow[b]{2}{*}{ Exclusion criteria } & \multirow{2}{*}{$\begin{array}{l}\text { Antibiotic } \\
\text { used }\end{array}$} & \multicolumn{4}{|c|}{ Oxford Quality Scale scores } \\
\hline & & & & Randomisation & Double-blinding & Withdrawals & Total \\
\hline $\begin{array}{l}\text { Wax } \\
\text { et } a \beta^{\beta}\end{array}$ & $\begin{array}{l}\text { Single fetus } \geq 37 \text { weeks of } \\
\text { gestation }\end{array}$ & $\begin{array}{l}\text { Penicillin or cephalosporin allergy, antibiotic use } \\
\text { within } 2 \text { weeks of delivery, temperature } \geq 37.8^{\circ} \mathrm{C} \text {, } \\
\text { administration of B streptococcal orsubacute } \\
\text { bacterial endocarditis prophylaxis, } \\
\text { insulin-dependent diabetes mellitus, human } \\
\text { immunodeficiency virus infection, chronic } \\
\text { glucocorticoid use, multiple gestation }\end{array}$ & $\begin{array}{l}\text { Cefazolin } \\
1 \mathrm{~g}\end{array}$ & 2 & 2 & 1 & 5 \\
\hline $\begin{array}{l}\text { Thigpen } \\
\text { et } a \hat{\rho}\end{array}$ & & $\begin{array}{l}\text { Acute chorioamnionitis, allergy to penicillin or } \\
\text { cephalosporins, caesarean section without } \\
\text { labour, systemic antibiotics within past } 2 \text { weeks }\end{array}$ & $\begin{array}{l}\text { Cefazolin } \\
2 \mathrm{~g}\end{array}$ & 2 & 2 & 1 & 5 \\
\hline $\begin{array}{l}\text { Sullivan } \\
\text { et } a l^{10}\end{array}$ & $>24$ weeks gestational age & $\begin{array}{l}\text { Cephalosporin allergy, age }<18 \text { years, antibiotic } \\
\text { exposure within } 1 \text { week of delivery, emergency } \\
\text { caesarean section }\end{array}$ & $\begin{array}{l}\text { Cefazolin } \\
1 \mathrm{~g}\end{array}$ & 2 & 2 & 1 & 5 \\
\hline $\begin{array}{l}\text { Nokiani } \\
\text { et } a l^{11}\end{array}$ & $\begin{array}{l}\text { Normal healthy women, afebrile, } \\
\text { amniotic membrane intact or } \\
\text { ruptured for not more than } 18 \mathrm{~h} \text {, } \\
\text { first caesarean section }\end{array}$ & $\begin{array}{l}\text { Confirmed systemic disease (diabetes mellitus, } \\
\text { hypertension, immune compromised diseases, } \\
\text { coagulation disorders, heart or renal failure) }\end{array}$ & $\begin{array}{l}\text { Cefazolin } \\
2 \mathrm{~g}\end{array}$ & 1 & 1 & 0 & 2 \\
\hline Witt et $a^{6}$ & $\begin{array}{l}\text { Gestational age } \geq 37 \text { weeks, } \\
\text { reassuring fetal heart traces; } \\
\text { rupture of membranes and labor } \\
\text { contractions were allowed }\end{array}$ & $\begin{array}{l}\text { Fever }>38^{\circ} \mathrm{C} \text {, cephalosporin allergy, age } \\
<18 \text { years, antibiotic exposure within } 1 \text { week } \\
\text { before delivery }\end{array}$ & $\begin{array}{l}\text { Cefazolin } \\
2 \mathrm{~g}\end{array}$ & 2 & 2 & 1 & 5 \\
\hline
\end{tabular}


(a)

Before skin incision After cord clamping

Risk Ratio

Risk Ratio

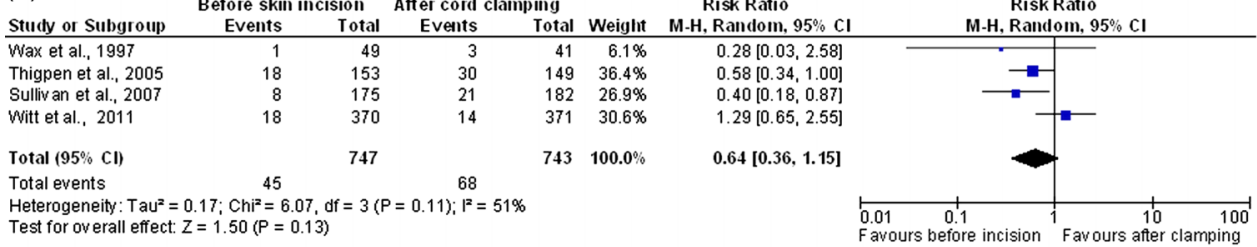

(b)

Before skin incision After cord clamping

Risk Ratio

Risk Ratio

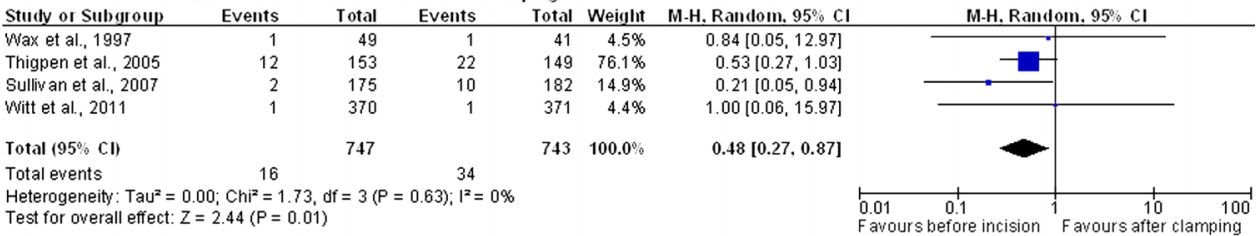

(c)

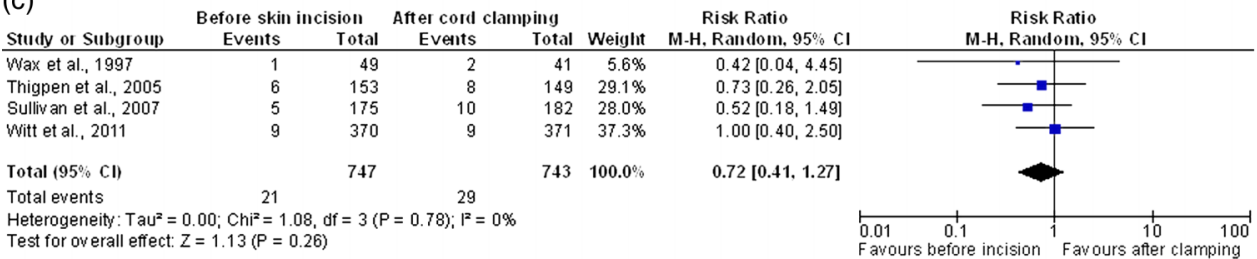

Figure 2 Maternal outcomes. (A) Total infectious morbidity, (B) endometritis and (C) wound infection.

(a)

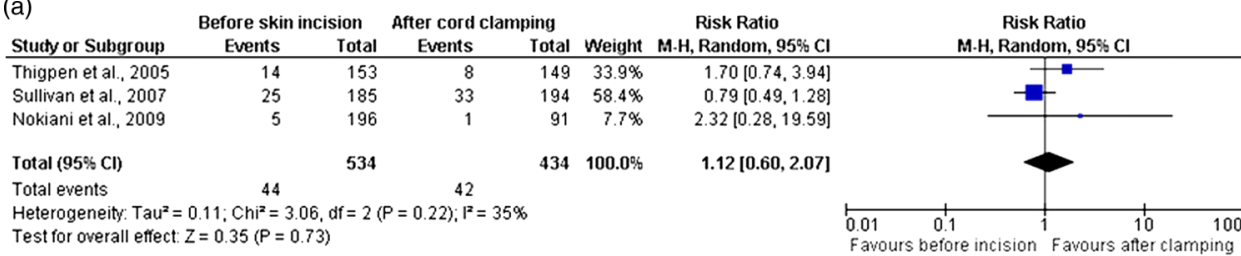

(b)

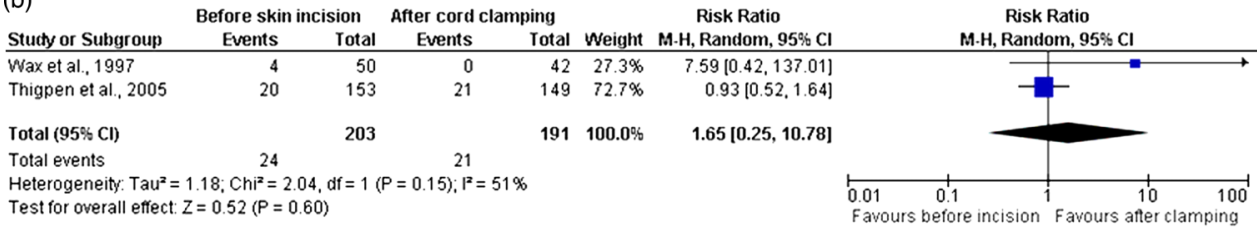

(c)

\begin{tabular}{|c|c|c|c|c|c|c|c|c|}
\hline \multirow[b]{2}{*}{ Stucty or Subgroup } & \multicolumn{2}{|c|}{ Before skin incision } & \multicolumn{2}{|c|}{ After cord clamping } & \multirow[b]{2}{*}{ Weight } & \multirow{2}{*}{$\begin{array}{c}\text { Risk Ratio } \\
\text { M.H, Random, } 95 \% \mathrm{Cl}\end{array}$} & \multirow{2}{*}{$\begin{array}{c}\text { Risk Ratio } \\
\text { M.H, Random, } 95 \% \mathrm{Cl}\end{array}$} & \\
\hline & Events & Total & Events & Iotal & & & & \\
\hline Thigpen et al., 2005 & 7 & 153 & 7 & 149 & $46.9 \%$ & $0.97[0.35,2.71]$ & & \\
\hline Sullivan et al., 2007 & 6 & 185 & 7 & 194 & $42.7 \%$ & $0.90[0.31 .2 .62]$ & & \\
\hline Nokiani et al., 2009 & 4 & 196 & 1 & 91 & $10.4 \%$ & $1.86[0.21,16.38]$ & & \\
\hline Total $(95 \% \mathrm{Cl})$ & & 534 & & 434 & $100.0 \%$ & $1.01[0.50,2.03]$ & & \\
\hline Total events & 17 & & 15 & & & & & \\
\hline $\begin{array}{l}\text { Heterogeneity } \mathrm{Tau}^{2} \\
\text { Test for overall effect }\end{array}$ & $\begin{array}{l}0.00 ; \mathrm{Chi}^{2}= \\
\mathrm{Z}=0.02(\mathrm{P}=\end{array}$ & $d f=2$ & $P=0.84) ; I^{2}$ & & & & $\begin{array}{lc}0.01 & 0.1 \\
\text { Favours before in }\end{array}$ & $\begin{array}{l}10 \\
10 \\
\text { after clamping }\end{array}$ \\
\hline
\end{tabular}

(d)

\begin{tabular}{|c|c|c|c|c|c|c|c|c|}
\hline \multirow[b]{2}{*}{ Stucty or Subgroup } & \multicolumn{2}{|c|}{ Before skin incision } & \multicolumn{2}{|c|}{ After cord clamping } & \multirow{3}{*}{$\frac{\text { Weight }}{33.3 \%}$} & \multirow{2}{*}{$\begin{array}{c}\text { Risk Ratio } \\
\text { M. H, Random, } 95 \% \mathrm{Cl}\end{array}$} & \multirow{2}{*}{$\begin{array}{c}\text { Risk Ratio } \\
\text { M.H, Random, } 95 \% \mathrm{Cl}\end{array}$} & \\
\hline & Events & Total & Events & Total & & & & \\
\hline Waxet al., 1997 & 6 & 49 & 2 & 41 & & $2.51[0.54,11.77]$ & & \\
\hline Thigpen et al., 2005 & 11 & 153 & 14 & 149 & $66.7 \%$ & $0.77[0.36,1.63]$ & & \\
\hline Total $(95 \% \mathrm{Cl})$ & & 202 & & 190 & $100.0 \%$ & $1.14[0.38,3.42]$ & & \\
\hline Total events & 17 & & 16 & & & & & \\
\hline \multicolumn{7}{|c|}{$\begin{array}{l}\text { Heterogeneity: Tau }{ }^{2}=0.32 ; \mathrm{Chi}^{2}=1.84, \mathrm{df}=1(P=0.17) ; 1^{2}=46 \% \\
\text { Test for overall effect: } Z=0.23(P=0.82)\end{array}$} & 0.01 & 10 \\
\hline
\end{tabular}

Figure 3 Neonatal outcomes. (A) Neonatal intensive care unit admission, (B) neonatal infection, (C) neonatal sepsis and

(D) suspected neonatal sepsis. 
In conclusion, evidence provided by double-blind RCTs suggests that only the risk for endometritis is reduced by antibiotic administration before skin incision; the corresponding NNT, that is, 41, is quite high. No differences between the early administration versus the administration after cord clamping were observed for other maternal and neonatal outcome parameters. Nevertheless, it is advisable to administer antibiotics before skin incision.

\section{Author affiliations}

${ }^{1}$ Department of Anaesthesiology, Klinikum Bamberg, Bamberg, Germany ${ }^{2}$ Department of Anaesthesiology, University Hospital Aachen, Aachen, Germany

${ }^{3}$ Department of Neonatology, University Hospital Leuven, Leuven, Belgium ${ }^{4}$ Department of Gynaecology, University Hospital Leuven, Leuven, Belgium ${ }^{5}$ Department of Anaesthesiology, University Hospital Leuven, Leuven, Belgium ${ }^{6}$ Department of Occupational, Social and Environmental Medicine, University Medical Center Göttingen, Göttingen, Germany

Contributors MH, SK, MVdV and SS conceived the idea of the study. MH and SK reviewed the articles. The quality scoring was performed by $\mathrm{MH}$ and SS. The data extraction and analysis was performed by MH and SK. SK produced the tables and graphs. The interpretation of the results was performed by MH, SK, RR, KA, JD, MVdV and SS. The initial draft of the manuscript was prepared by $\mathrm{MH}$ and SS and then circulated repeatedly among all authors for critical revision. All authors read and approved the final manuscript.

Funding This research received no specific grant from any funding agency in the public, commercial or not-for-profit sectors.

Competing interests None.

Provenance and peer review Not commissioned; externally peer reviewed.

Data sharing statement The data of the meta-analysis are available from michael.heesen@sozialstiftung-bamberg.

\section{REFERENCES}

1. National Institute for Health and Clinical Excellence. CG132 Caesarean Section. http://guidance.nice.org.uk/CG132

2. Cantwell R, Clutton-Brock T, Cooper G, et al. Saving mothers' lives: reviewing maternal deaths to make motherhood safer: 2006-2008. The eighth report of the confidential enquiries into maternal deaths in the United Kingdom. BJOG 2011;118(Suppl 1):1-203.

3. Fiore Mitchell T, Pearlman MD, Chapman RL, et al. Maternal and transplacental pharmacokinetics of cefazolin. Obstet Gynecol 2001;98:1075-9.

4. Gordon HR, Phelps D, Blanchard K. Prophylactic cesarean section antibiotics: maternal and neonatal morbidity before or after cord clamping. Obstet Gynecol 1979;53:151-6.

5. Yildirim G, Gungorduk K, Guven HZ, et al. When should we perform prophylactic antibiotics in elective cesarean cases? Arch Gynecol Obstet 2009;280:13-18.

6. Witt A, Döner M, Petricevic L, et al. Antibiotic prophylaxis before surgery vs after cord clamping in elective cesarean delivery: a double-blind, prospective, randomized, placebo-controlled trial. Arch Surg 2011;146:1404-9.

7. Jadad AR, Moore RA, Carroll D, et al. Assessing the quality of reports of randomized clinical trials: is blinding necessary? Control Clin Trials 1996;17:1-12.

8. Wax JR, Hersey K, Philput C, et al. Single dose cefazolin prophylaxis for postcesarean infections: before vs. after cord clamping. J Matern Fetal Med 1997;6:61-5.

9. Thigpen BD, Hood WA, Chauhan S, et al. Timing of prophylactic antibiotic administration in the uninfected laboring gravida: a randomized clinical trial. Am J Obstet Gynecol 2005;192:1864-8.

10. Sullivan SA, Smith T, Chang E, et al. Administration of cefazolin prior to skin incision is superior to cefazolin at cord clamping in preventing postcesarean infectious morbidity: a randomized, controlled trial. Am J Obstet Gynecol 2007;196:455.e1-5.

11. Nokiani FA, Akbari H, Rezaei M. Timing of prophylactic antibiotic administration in term cesarean sections: a randomized clinical trial. Iran J Clin Infect Dis 2009;42:71-6.

12. Kaimal AJ, Zlatnik MG, Cheng YW, et al. Effect of a change in policy regarding the timing of prophylactic antibiotics on the rate of postcesarean delivery surgical-site infections. Am J Obstet Gynecol 2008;199:310.e1-5.

13. Owens SM, Brozanski BS, Meyn LA, et al. Antimicrobial prophylaxis for cesarean delivery before skin incision. Obstet Gynecol 2009;114:573-9.

14. Fejgin MD, Markov S, Goshen S, et al. Antibiotic for cesarean section: the case for 'true' prophylaxis. Int J Gynaecol Obstet 1993;43:257-61. 


\section{Correction}

Heesen M, Klöhr S, Rossaint R, et al. Concerning the timing of antibiotic administration in women undergoing caesarean section: a systematic review and meta-analysis. BMJ Open 2013;3:e002028. One of the authors' surnames is spelt incorrectly. 'Karel Allegeaert' should be 'Karel Allegaert'.

BMJ Open 2013;3:e002028corr1. doi:10.1136/bmjopen-2012-002028corr1 